\title{
A Fiber Bragg Grating (FBG)-Enabled Smart Washer for Bolt Pre-Load Measurement: Design, Analysis, Calibration, and Experimental Validation
}

\author{
Dongdong Chen ${ }^{1}(\mathbb{D})$, Linsheng Huo ${ }^{1, *(\mathbb{D})}$, Hongnan $\mathrm{Li}^{1,2}$ and Gangbing Song ${ }^{3, *(1)}$ \\ 1 State Key Laboratory of Coastal and Offshore Engineering, Dalian University of Technology, Dalian 116024, \\ China; chendongdlut@mail.dlut.edu.cn (D.C.); hnli@dlut.edu.cn (H.L.) \\ 2 School of Civil Engineering, Shenyang Jianzhu University, Shenyang 110168, China \\ 3 Smart Material and Structure Laboratory, Department of Mechanical Engineering, University of Houston, \\ Houston, TX 77204, USA \\ * Correspondence: lshuo@dlut.edu.cn (L.H.); gsong@uh.edu (G.S.)
}

Received: 3 July 2018; Accepted: 5 August 2018; Published: 7 August 2018

\begin{abstract}
A washer is a common structural element that is directly used along the loading path of a bolted connection. Pre-load on a bolted connection directly impacts its load bearing capacity and pre-load monitoring is an important aspect of structural health monitoring (SHM). With the change of the pre-load on a bolted connection, the loading force on the washer will change and, therefore, the outer diameter and outer circumferential length of the washer will change. Taking advantage of the high sensitivity and the small size of a Fiber Bragg Grating (FBG) sensor, we propose an innovative smart washer encircled by an FBG sensor that can directly measure the circumferential strain change and, therefore, the pre-load on the washer. For protection, the FBG is embedded in a pre-machined groove along the circumferential surface of the washer. A theoretical approach is used to derive the linear relationship between the applied load and the circumferential strain of the washer. To validate the functionality of the FBG-enabled smart sensor for in situ bolt pre-load monitoring, a simple but effective testing apparatus is designed and fabricated. The apparatus involves a bolt, the FBG-enabled washer, a metal plate, and a nut. The bolt has an embedded FBG along its axial direction for precise axial strain and, therefore, force measurement. With the calibrated axial force measuring bolt, in situ experiments on the FBG-enabled smart washers are conducted. Experimental results reveal the linear relationship between the pre-load and the wavelength of the FBG sensor encircling the washer. Both analytical and experimental results demonstrate that the proposed novel approach is sensitive to the bolt pre-load and can monitor in real time the bolt looseness in the entire loading range.
\end{abstract}

Keywords: bolt pre-load measurement; bolt looseness monitoring; bolted connection monitoring; Fiber Bragg Gratings (FBG); FBG-enabled smart washer; smart washer

\section{Introduction}

As one of the most common types of structural connection, bolted joints are commonly used in civil structures, such as long-span bridges and high-rise buildings [1,2]. The pre-load of a bolt connection directly impacts its load bearing capacity and plays an important role in the structural wellbeing [1,2]. With the recent emphasis on and development of Structural Health Monitoring (SHM) [3-7], bolt pre-load monitoring has begun to receive attention and various methods have been proposed [8-10]. Wang et al. [11] conducted a review on bolted connection monitoring, which reviewed the acoustoelastic method [12], the piezoelectric active sensing method [13], and the piezoelectric impedance method [14]. 
The principle of the acoustoelastic method is based on the velocity difference of the ultrasonic wave at different axial stresses. Yasui et al. [15] proposed a new acoustoelastic axial stress measurement method in which both longitudinal and transverse waves were excited simultaneously by a combined Longitudinal/Shear (L/S) mode transducer. However, the method requires bulky equipment for accurate measurement of the ultrasonic velocity and is not suitable for real-time monitoring. On the other hand, the piezoelectric active sensing method needs only two small piezoceramic patches, which are bonded on different parts of the bolted connection, and a relatively inexpensive data acquisition system [16]. Due to its strong piezoelectric effect, Lead Zirconate Titanate (PZT) is the most commonly used piezoceramic material. In the active sensing approach, one PZT transducer is used as an actuator to generate a stress wave, and the other transducer is used as a sensor to detect the propagated wave. The generated wave travels along the loading path and crosses the interface of the bolted connection, and the propagated stress wave will then be detected by the piezoceramic sensor. The pre-load on a bolt connection directly impacts the interface of the connection, and a larger force ensures a better connection, resulting in better wave propagation with less energy dissipation. On the other hand, a lesser force creates a poor connection, resulting in poor wave propagation with more energy dissipation. A novel PZT-based smart washer was proposed by Huo et al. [17] to enable the active sensing approach for bolted connections. The PZT-based smart washer was formed by embedding a PZT patch between two metal rings. With its sensing and actuating abilities, the washer can detect the bolt pre-load looseness level through the active sensing approach. For the PZT-based active sensing method, saturation occurred when the applied torque reached a certain high value $[16,17]$, and the method cannot detect the looseness when the saturation occurs. The theoretical analysis performed by Huo et al. [18] also validated this saturation phenomenon.

In addition, the piezoelectric impedance method has been applied to detect damage [19-22] and was first presented by Liang et al. [23]. A real-time damage detection method based on PZT impedance was investigated in pipes connected by bolted joints [24]. Data collected from the tests illustrated the capability of this method to detect the loosening of the bolted joints. A bolted loosening experiment was conducted in the work of Park et al. [25]. In their research, the mechanical impedance sensing region was investigated in a 1/4-scale bridge section specimen. Recently, the applications of wireless monitoring systems have increased rapidly [26]. Perera et al. developed a flexible wireless smart sensor (WSS) framework based on the Electromechanical Impedance (EMI) method using active sensors for full-scale and autonomous SHM [27]. With the help of unmanned aerial vehicles (UAVs), an impedance-based nondestructive health monitoring method was proposed by Na et al. [28]. In general, the impedance method is a qualitative approach to detecting local damage. This approach cannot detect minor looseness of bolt connections. In addition, piezoceramic-based active sensing or impedance methods are not suitable for monitoring systems with strong electric or magnetic fields, such as those near transformers or electric power lines.

In the structural health monitoring field, Fiber Optical Sensors (FOSs) have been widely used [29,30], including in civil structures [31], aviation [32], oil and gas [33], nuclear power plants [34], and other fields [18,35]. A Fiber Bragg Grating (FBG) is a common fiber optical sensor and has the advantages of small size, high sensitivity, electromagnetic immunity (EMI), and suitability for embedment. Plenty of studies have referred to bolt tension monitoring using FBG sensors. A bolt tension monitoring device was proposed by Khomenko et al. [36], and it utilizes removable and reusable fiber Bragg grating sensor(s) embedded in a bolt shaft for pre-load and retained clamping force measurements. They found that, depending on the joint configuration, the pre-load reduction varied considerably, and an increase in initial pre-load tended to reduce the pre-load relaxation [37]. Although this device can directly detect the defects of bolt joints, a drilled hole along the axis of the bolt through one-half of its length was required, and the drilled holed may reduce the bearing capacity of the bolt. Yeager et al. [38] presented an embedded fiber Bragg grating sensor by using the full width at half-maximum bandwidth of the Bragg reflection spectrum for monitoring the pre-load torque in a composite bolted connection. 
This paper proposes a new approach to quantitative bolt looseness monitoring by using a Fiber Bragg Grating enabled smart washer for the entire range of the applied torque. In this research, the FBG sensor was embedded into a pre-machined circumferential groove which was located in the exterior washer surface. Since the washer is directly on the loading path of a bolted connection, the FBG-enabled smart washer is very sensitive to the pre-load changes and it can continue to monitor the pre-load during the entire loading range. By analyzing the wavelength change, different bolt looseness statuses can be monitored quantitatively. Experimental results demonstrate that the FBG-enabled smart washer is a simple, feasible, and quantitative method to monitor the pre-load level.

\section{Fiber Bragg Grating (FBG)-Enabled Smart Washer: Principle and Design}

The fiber Bragg grating, as shown in Figure 1, is a wavelength-dependent filter/reflector formed by introducing a periodic refractive index structure, with spacing on the order of a wavelength of light, within the core of an optical fiber [39]. When a light passes through the grating at a particular wavelength, called the Bragg wavelength, the light will be reflected [40]. The Bragg wavelength is expressed as

$$
\lambda_{B}=2 n \Lambda
$$

where $\lambda_{B}$ is the Bragg wavelength, $n$ is the effective refractive index of the FBG, and $\Lambda$ is the grating period.

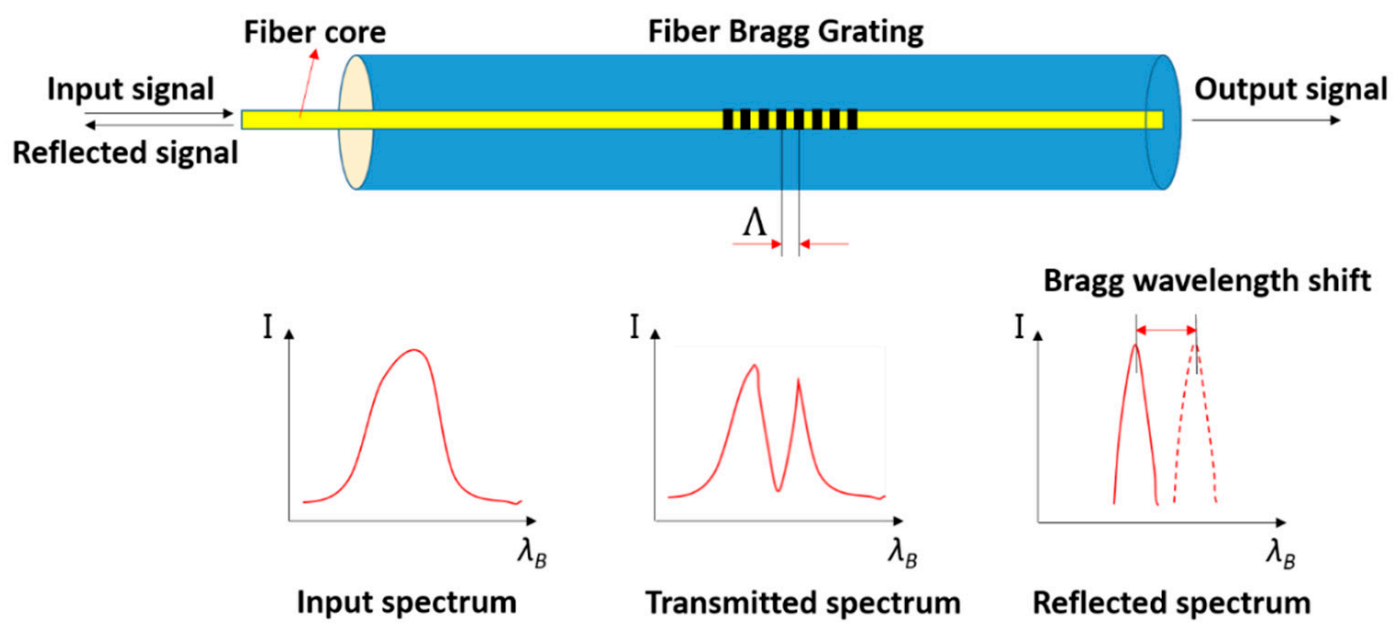

Figure 1. Schematic diagram of a fiber Bragg grating (FBG) sensor.

When a broad-spectrum light signal is input to the Fiber Bragg Grating section, a reflected spectrum whose center wavelength is $\lambda_{B}$ will be reflected and the remaining portion of light will transmit through. The reflected light can be used as an index to measure strain, temperature, or polarization changes by the Bragg wavelength shift. In this study, a commercially available coated FBG sensor was used to enable a washer to have the function to monitor the pre-load of a bolted connection. The length of the Bragg grating is $10 \mathrm{~mm}$, the outer diameter of the fiber is $250 \mu \mathrm{m}$, and the diameter of the optical fiber core is $9 \mu \mathrm{m}$.

The smart washer design is illustrated in Figure 2a. The smart washer is formed by encircling the washer by an optical fiber with an FBG sensor. First of all, a smooth groove was pre-machined along the outer surface of the washer. Then, 502 glue was used to bond the fiber to the washer, after the sensor was attached to the washer. Epoxy resin was then used to strengthen the strain transfer between fiber and washer. Last, 704 glue was used to protect the fiber from damage. Figure $2 b$ shows photos of a fabricated smart washer. In this research, the inner and outer diameters of the smart washer are $23 \mathrm{~mm}$ and $37 \mathrm{~mm}$, respectively. The height is $5 \mathrm{~mm}$. The depth and width of the groove are $1.5 \mathrm{~mm}$ and $2 \mathrm{~mm}$, respectively. With the change of the pre-load on a bolted connection, the loading force 
on the washer will change and, therefore, the outer diameter and outer circumferential length of the washer will change, which is directly measured by the FBG sensor. Taking advantage of the FBG sensor, including its high sensitivity, the proposed smart washer can accurately measure the pre-load on a bolted joint and detect the looseness of a bolted joint, as demonstrated in later sections.

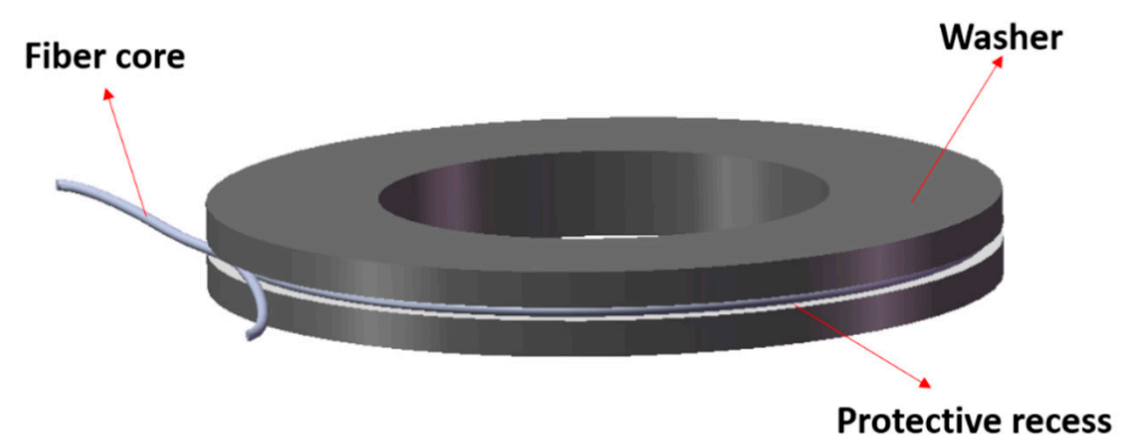

(a)

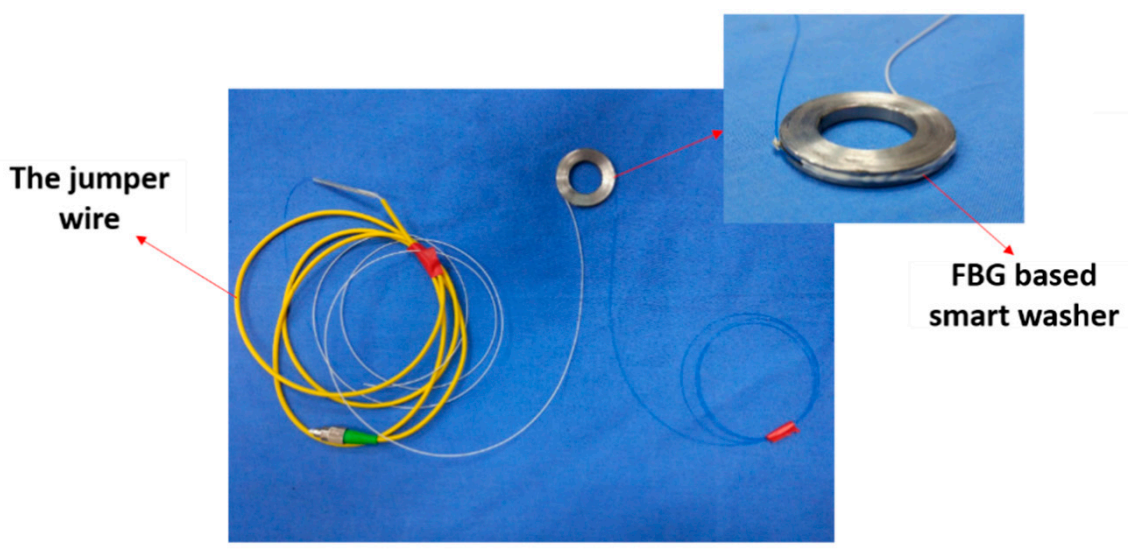

(b)

Figure 2. The FBG-enabled smart washer sensor. (a) The design diagram of the FBG-enabled smart washer; (b) Photos of the FBG-enabled smart washer.

For the smart washer with the FBG sensor, the delicate part is the fiber with gratings (about $10 \mathrm{~mm}$ ), which is embedded in the pre-machined groove on the washer with protection of glue and epoxy. The rest of the fiber can use commercially available steel-reinforced or Kevlar-reinforced fiber. Therefore, the smart washer design is suitable for practical applications.

\section{Smart Washer-An Analytical Model}

The smart washer that is proposed to monitor the bolt pre-load looseness is based on monitoring of the circumferential strain change by an FBG sensor whose wavelength changes with the circumferential strain. It is necessary to analyze the relationship between the pre-load and the circumferential strain. An in-service washer model is shown in Figure 3, which clearly shows that pre-load on the washer induces circumferential strain changes for the washer. 


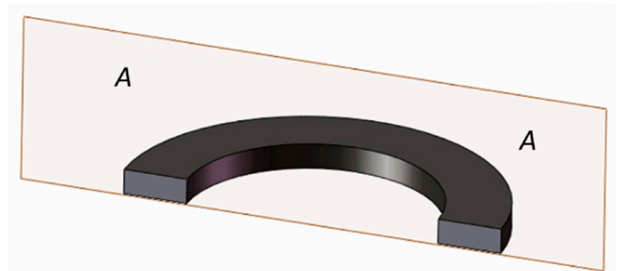

(a)

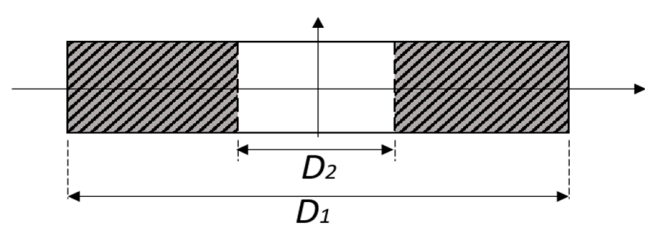

(b)

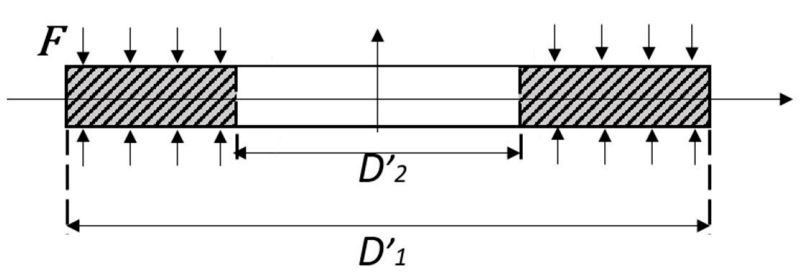

(c)

Figure 3. Figures to illustrate that pre-load changes induce circumferential strain change of a washer. (a) A 3D view of a washer with A-A cross-sectional view; (b) A 2D A-A cross-sectional view of washer without torque applied; (c) The 2D A-A cross-sectional view of washer with torque applied.

An axial force on the bolt results in a uniform stress on the washer upper and lower surfaces, and the stress change can be expressed as

$$
\Delta \sigma=\frac{F}{A}
$$

where $\Delta \sigma$ is the axial stress change of the washer, and $A$ is the washer's upper surface area which is given as

$$
A=\frac{\pi\left(\left(D_{1}\right)^{2}-\left(D_{2}\right)^{2}\right)}{4}
$$

where $D_{1}$ and $D_{2}$ are the external and internal nominal diameters of the washer without torque applied, and $D_{1}^{\prime}$ and $D_{2}^{\prime}$ are the external and internal nominal diameters of the washer with torque applied as shown in Figure $3 b, c$. The axial strain change which is represented as $\Delta \varepsilon_{l}$ is introduced as

$$
\Delta \varepsilon_{l}=\frac{\Delta \sigma}{E}
$$

where $E$ is the Young's modulus of the washer. According to the Poisson ratio, the transverse strain change $\Delta \varepsilon_{D}$ can be expressed as

$$
\Delta \varepsilon_{D}=\mu \Delta \varepsilon_{l}
$$

Please note that the $\Delta \varepsilon_{D}$ can also be expressed as

$$
\Delta \varepsilon_{D}=\frac{\Delta D_{1}}{D_{1}}=\frac{D_{1}^{\prime}-D_{1}}{D_{1}}
$$


where $\Delta D_{1}$ is the pre-load decrease caused the external nominal diameter change, and the circumferential strain $\Delta \varepsilon_{\mathcal{C}}$ is given as

$$
\Delta \varepsilon_{C}==\frac{\Delta C_{1}}{C_{1}}=\frac{2 \pi D_{1}^{\prime}-2 \pi D_{1}}{2 \pi D_{1}}=\frac{\Delta D_{1}}{D_{1}}
$$

where $C_{1}$ is the external circumferential without torque applied, and $\Delta C_{1}$ is the pre-load decrease caused by the external perimeter change.

The relationship between the embedded Bragg wavelength change $\Delta \lambda_{w}$ and the washer strain change $\Delta \varepsilon_{\mathcal{C}}$ can be presented as

$$
\Delta \lambda_{\omega}=k_{w} \Delta \varepsilon_{c}
$$

where $k_{w}$ is the strain sensitivity coefficient. From Equations (6) and (7), we know that $\Delta \varepsilon_{c}$ is equal to $\Delta \varepsilon_{D}$. Substituting Equations (1)-(6) into Equation (7) gives the expression of $\Delta \varepsilon_{\mathcal{C}}$ as

$$
\Delta \varepsilon_{C}=\Delta \varepsilon_{D}=\frac{\Delta D_{1}}{D_{1}}=\mu \Delta \varepsilon_{l}=\mu \frac{\Delta \sigma}{E}=\mu \frac{F}{A E}=\mu \frac{4 F}{\pi E\left(\left(D_{1}\right)^{2}-\left(D_{2}\right)^{2}\right)} .
$$

There is a linear relationship between the torque and the washer circumferential strain. The FBG wavelength can be expressed as

$$
\lambda_{c}=k_{w} \Delta \varepsilon_{c}+\lambda_{i}=k_{w} \mu \frac{4 F}{\pi E\left(\left(D_{1}\right)^{2}-\left(D_{2}\right)^{2}\right)}+\lambda_{i}
$$

where $\lambda_{i}$ is the initial wavelength, and $\mu$ and $E$ are, respectively, the Poisson's ratio and Young's modulus of the washer.

\section{Smart Washer-Calibration}

The relationship between the axial stress and the wavelength of the FBG sensor was investigated though calibration tests. Figure 4 shows the calibration setup of the calibration test.

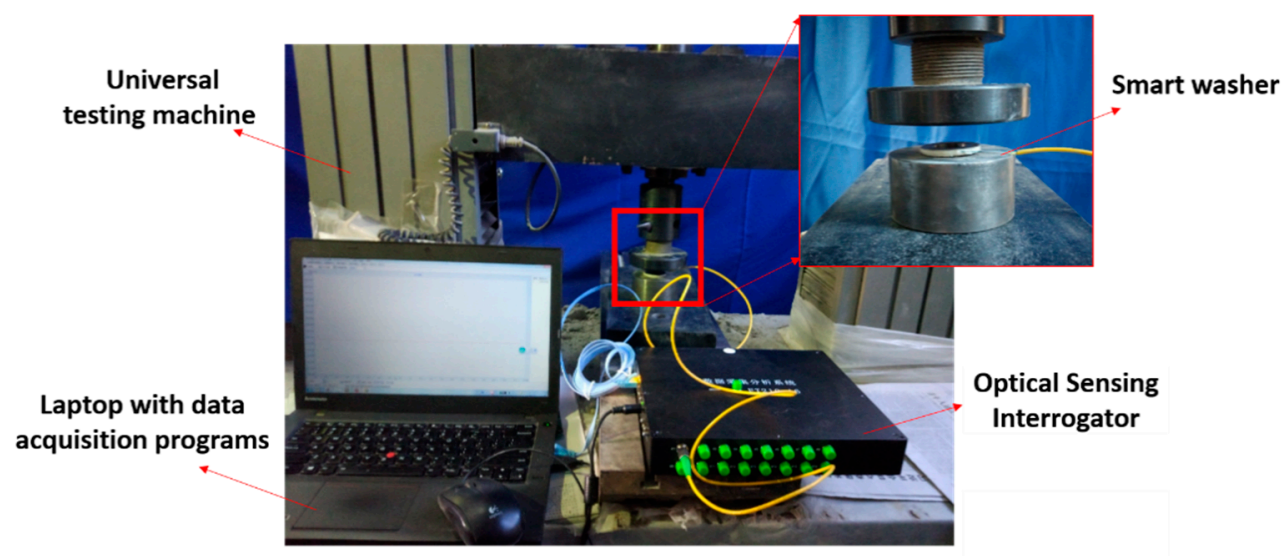

Figure 4. Calibration test of the FBG smart washer.

The smart washer was loaded continuously from $0 \mathrm{kN}$ to $20 \mathrm{kN}$ with a load speed of $200 \mathrm{~N} / \mathrm{s}$. The strain change of the washer can be recorded by the universal testing machine. Three calibration tests were implemented and the results are plotted in Figure 5. Please note that the values of both the strain (the left ordinate) and the axial force (the right ordinate) are shown in Figure 5. The average experimental strain sensitivity coefficient of the FBG sensor is $0.8040 \mu \varepsilon / \mathrm{pm}$. The coefficient of regression association can be calculated by following equation and is found to be 0.9995 : 


$$
R^{2}=\frac{\sum_{i=1}^{n}\left(\hat{y}_{i}-\bar{y}\right)^{2}}{\sum_{i=1}^{n}\left(y_{i}-\bar{y}\right)^{2}}
$$

where $\hat{y}_{i}$ and $y_{i}$ are the calculated regression value and measured value at the $i$ th point, and $\bar{y}$ is the mean value of all measured sample points.

It is shown that the FBG smart washer sensor is stable and capable of measuring the axial stress level, which demonstrates the potential of the smart washer to monitor the looseness of a bolted connection. In addition, we did not experience noticeable loss of the light intensity for the washer that we have used during the experiments. We also noticed that there is no saturation in Figure 5, which shows the advantage of the FBG-based smart washer over the piezoceramic-based active sensing method which has the saturation issue [15-17].

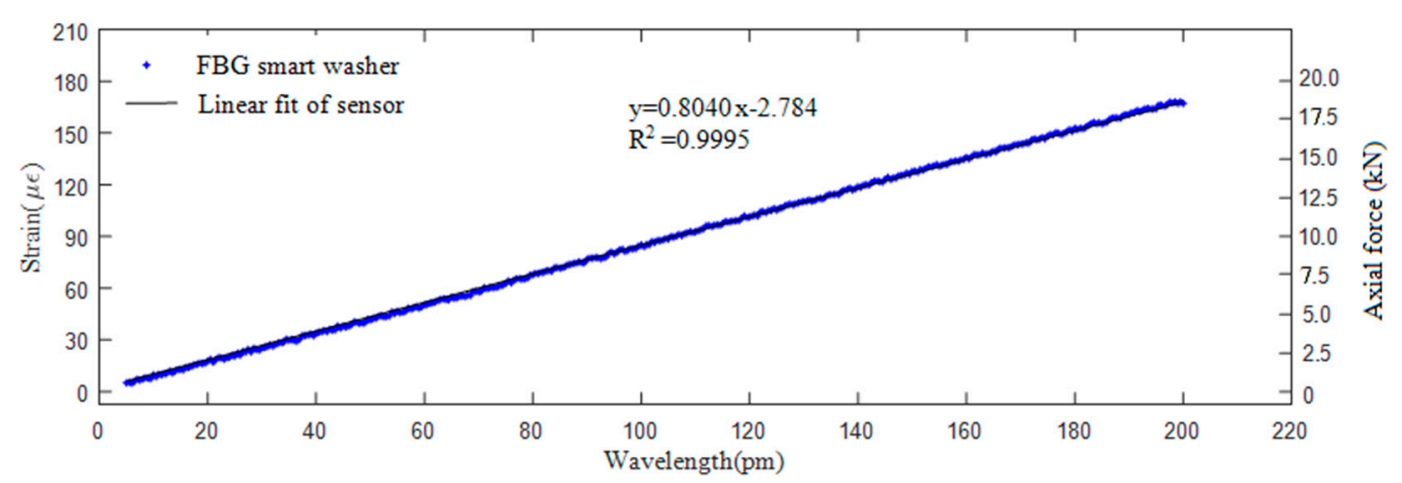

Figure 5. Calibration results of the smart washer.

\section{Bolt Looseness Monitoring Experiments Using Smart Washer}

\subsection{Experimental Setup}

As shown in Figure 6, the bolt looseness test specimen, which consists of one metal plate, a bolt, and a nut with an option of adding a washer, is used in the research. The pre-load on the bolt is controlled by a torque wrench and the stress on the bolt is measured by a smart bolt that has an embedded FBG sensor. The experimental setup is illustrated in Figure 7. The torque wrench is used to apply the required torque to the specimen to explore the relationship between the applied torque and the bolt axial force that is measured by the smart bolt.

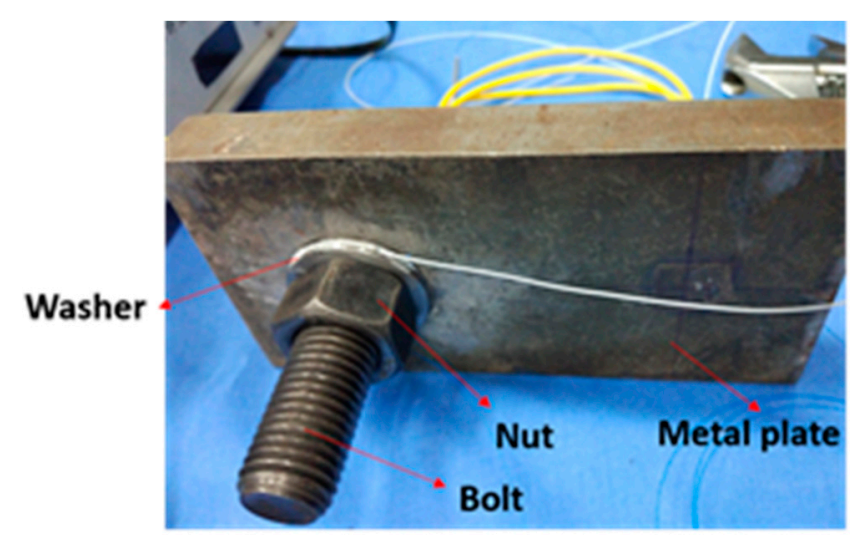

Figure 6. Calibration test of the FBG smart washer. 


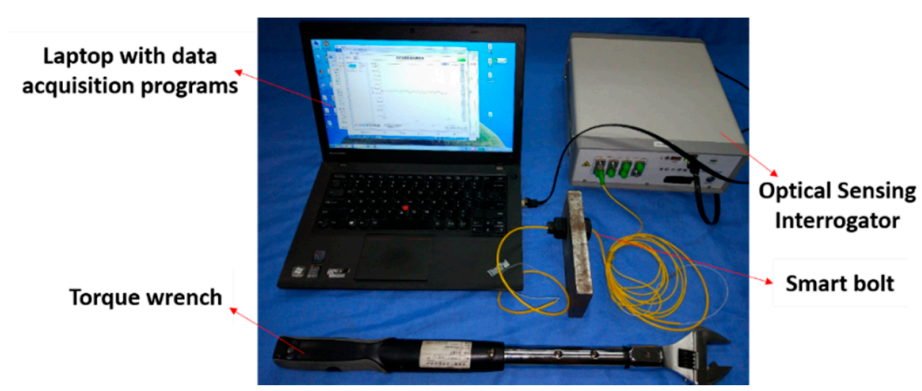

Figure 7. Experimental setup of external torque and bolt tension relationship verification.

The smart bolt was made by embedding a specially treated FBG sensor which includes two gripper tubes and two mounting supports into the center of the bolt. More detailed information can be found in [41]. With the help of the FBG sensor, the smart bolt can measure the axial forces when an external torque is applied. The design and a photo of the smart bolt are shown in Figures 8 and 9 , respectively.

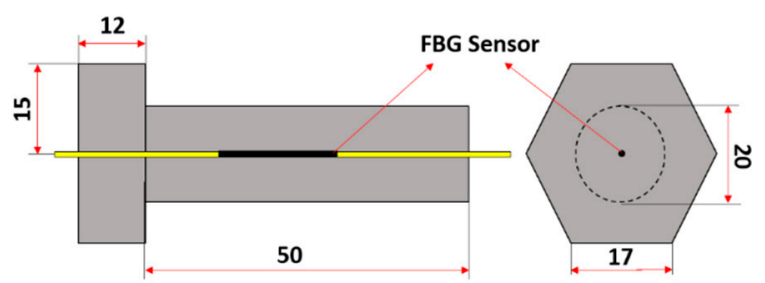

Figure 8. The design of a smart bolt with an embedded FBG sensor.

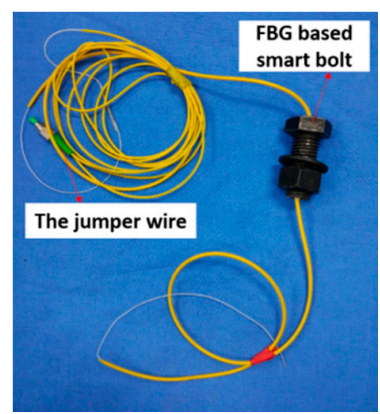

Figure 9. A photo of the FBG-based smart bolt that is used to measure the axial loading.

\subsection{Relationship Between Pre-Load and External Torque with Help from a Smart Bolt}

In the monitoring process, the bolted connection with a smart washer was fastened by applying external torque. Therefore, the relationship between applied torque and the axial load of the bolt should be first studied. The mechanical behavior of bolted joints during loosening and fastening was investigated [42-45]. The research results show that the torque applied to a bolted connection consists of three components [43,46]: (1) the torque to stretch the bolt; (2) the torque to overcome the friction in the threads of the bolt; and (3) the friction between nut face and bearing surface. In practice, it is appropriate to use the following equation to determine the torque to achieve a certain pre-load [47]:

$$
F=\frac{T}{k \cdot d}
$$

where $F$ is the axial pre-load of the bolt, $T$ is the applied torque, $k$ is the torque-axial load coefficient determined by factors such as bolt type and lubricant, and $d$ is the nominal diameter of the bolt. 
The relationship between the smart bolt strain change $\Delta \varepsilon_{B}$ and the embedded Bragg wavelength change $\Delta \lambda_{B}$ can be presented as

$$
\Delta \varepsilon_{B}=k_{b} \Delta \lambda_{B}
$$

where $k_{b}$ is the strain transfer constant coefficients. According to Equation (13), the Bragg wavelength change linearly corresponds to the smart bolt strain change. The bolt axial stress change $\Delta \sigma_{B}$ is also linear with the strain change $\Delta \varepsilon_{B}$ as

$$
\Delta \varepsilon_{B}=\frac{\Delta \sigma_{B}}{E_{B}}
$$

where the $E_{B}$ is the Young's modulus of the bolt. The bolt axial stress change $\Delta \sigma_{B}$ can be expressed as

$$
\Delta \sigma_{B}=\frac{F}{\pi(d / 2)^{2}}
$$

Substituting Equations (12)-(14) into Equation (15) gives the relationship between the applied torque $T$ and the Bragg wavelength change $\Delta \lambda_{B}$ as

$$
\Delta \lambda_{B}=\frac{T}{E_{B} k_{b} k \pi d(d / 2)^{2}} .
$$

To study the relationship between the axial force and the applied torque, an experiment using the FBG smart bolt [39] to monitor the axial force was conducted. Because of the limitations of the torque wrench, it can only measure the increased torque. Therefore, the reversed process of pre-load looseness was investigated this study.

The designed torque loading process is from $0-120 \mathrm{~N} \cdot \mathrm{m}$ at intervals of $10 \mathrm{~N} \cdot \mathrm{m}$. Since the torque in this paper was applied by a manual torque wrench, there was variation in torque increment in each loading case. In order to specifically show the relationship between the external torque and wavelength change, Figure 10 is plotted and a perfect linear fitting line between the external torque and wavelength change is obtained. Please note that the values of both Bragg wavelength (the left ordinate) and the axial force (the right ordinate) are shown in Figure 5. The linear relationship validates the correctness of the analysis of Equation (16), which confirms that the FBG-based smart bolt is an accurate tool to measure the axial loading on a bolted connection.

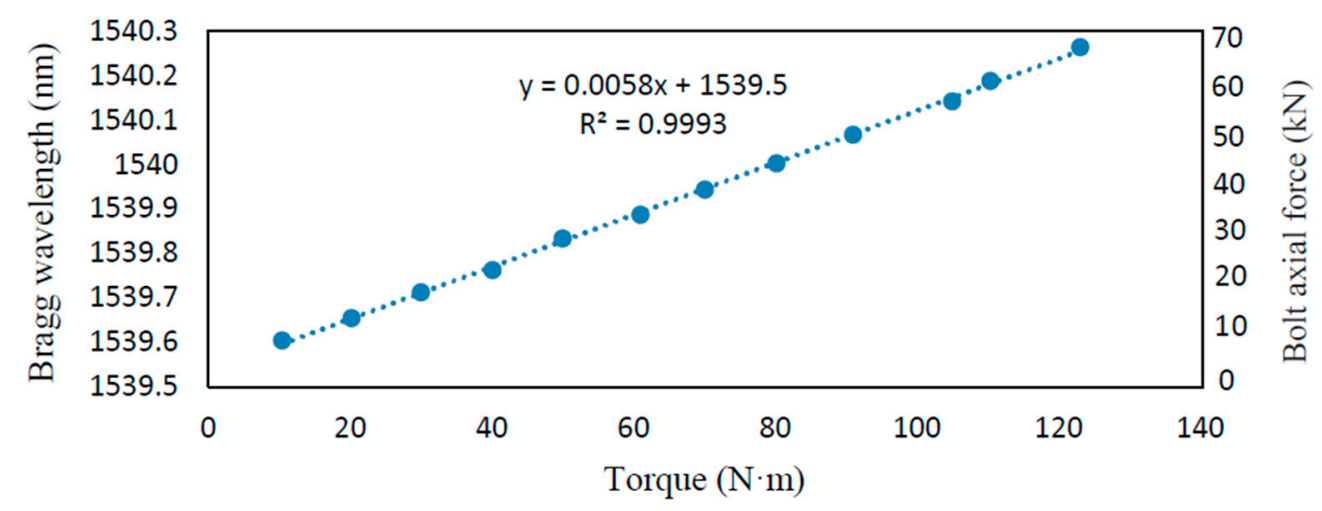

Figure 10. Experimental results of the linear relationship between the external torque and the Bragg wavelength changes.

\subsection{Quantitative Monitoring of Bolt Pre-Load Using an FBG-Based Smart Washer}

In this experiment, the pre-load is also controlled by the torque wrench. The instrumentation of the quantitative monitoring of the bolt pre-load is the same as that shown in Figures 6 and 7. 
The bolt pre-load loading process is from $0-120 \mathrm{~N} \cdot \mathrm{m}$ at intervals of $10 \mathrm{~N} \cdot \mathrm{m}$. With the increase of applied torque, the Bragg wavelength changes, as shown in Figure 11.

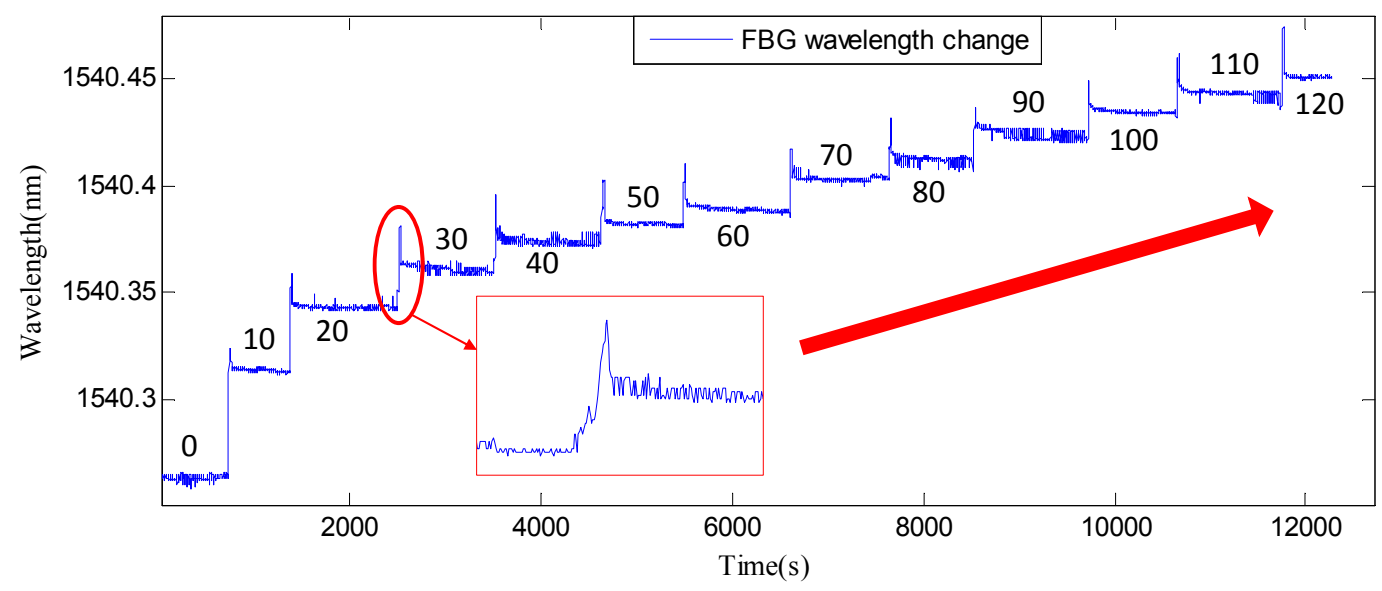

Figure 11. The Bragg wavelength change of the smart washer with the increased torque (Unit: $N \cdot m)$.

As shown in Figure 11, each step of the wavelength change is caused by the increased torque with an interval of $10 \mathrm{~N} \cdot \mathrm{m}$ from $0-120 \mathrm{~N} \cdot \mathrm{m}$. Based on Figure 11, the relationship between the FBG wavelength and the axial force (pre-load) versus the applied torque based on experimental data is shown in Figure 12. Please note that the values of both the FBG wavelength (the left ordinate) and the axial force (the right ordinate) are shown in Figure 12. It is clear that a linear relationship is achieved without saturation.

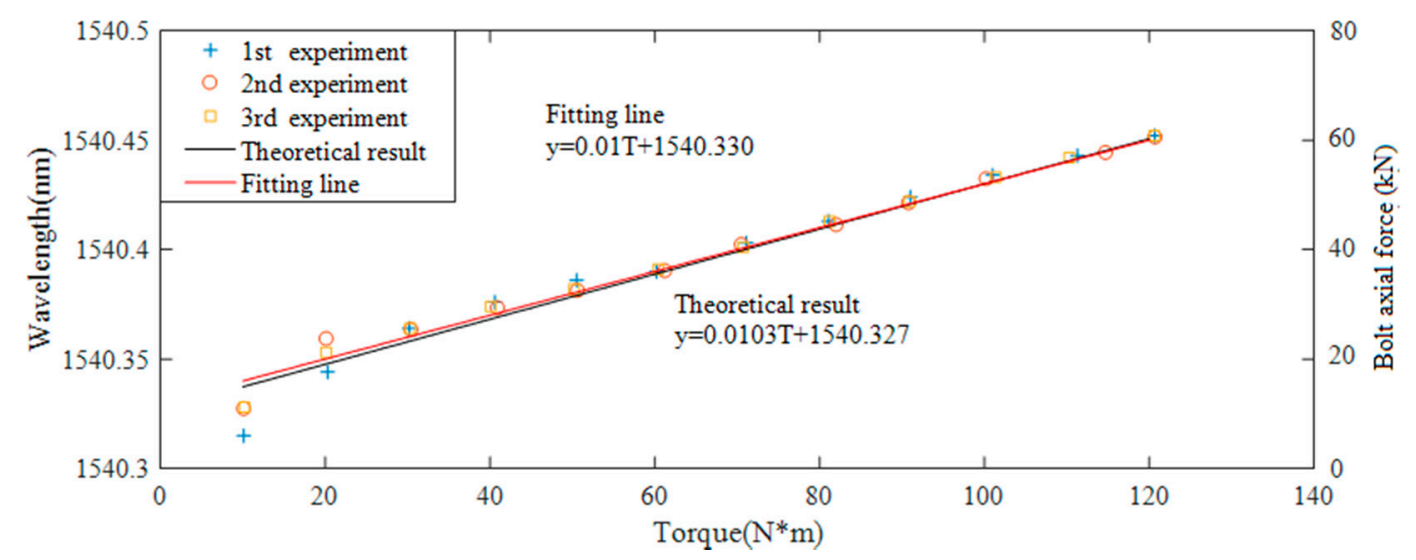

Figure 12. The comparison of theoretical and experimental results.

\section{Validation between Theoretical and Experimental Results}

In order to validate the analytical model, a comparison study of theoretical and experimental results was conducted. Substituting Equation (12) into Equation (10), the relationship between torque and the FBG smart washer wavelength can be expressed as

$$
\lambda_{c}=k_{w} \cdot \Delta \varepsilon_{c}+\lambda_{i}=k_{w} \cdot \mu \cdot \frac{4 * T}{\pi \cdot E \cdot k \cdot d \cdot\left(\left(D_{1}\right)^{2}-\left(D_{2}\right)^{2}\right)}+\lambda_{i}
$$

In this experiment, $k_{w}$ is 0.8040 , which can be obtained from the calibration test; $\mu$ and $E$ are the Poisson's ratio and Young's modulus of the washer, which are 0.32 and $2 \times 10^{5} \mathrm{Mpa}$, respectively; $k$ is 0.1 ; and $d$ is the nominal diameter of the bolt, which is $0.02 \mathrm{~m}$ in this experiment. In addition, $D_{1}$ and 
$D_{2}$ are $0.037 \mathrm{~m}$ and $0.023 \mathrm{~m}$, respectively. The comparison of the theoretical and three experimental results is plotted in Figure 12.

In Figure 12, it can be seen that when the torque is larger than $30 \mathrm{~N} \cdot \mathrm{m}$, the increase of the wavelength is around $10 \mathrm{pm}$ when the torque has a $10 \mathrm{~N} \cdot \mathrm{m}$ increase. The results show that it is feasible to detect the pre-load degradation by monitoring circumferential strain change of the fabricated smart washer with good repeatability. The linear relationship was obtained based on the repeated experimental data when the applied torque is higher than $30 \mathrm{~N} \cdot \mathrm{m}$. The comparison shows that the theoretical analysis is slightly close to the experimental results. The experimental results validate the analytical ones. Once again, there is no saturation in Figure 12, which clearly shows the advantage of the FBG-based smart washer over the piezoceramic-based active sensing method which has the saturation issue [15-17].

\section{Conclusions and Future Work}

This paper developed a simple but effective Fiber Bragg Grating (FBG)-enabled smart washer to monitor the pre-load of a bolt connection and to detect bolt looseness during its entire loading range. The smart washer was formed by encircling the washer by an optical fiber with an FBG sensor that was embedded in a pre-machined groove along the outer surface of the washer. A theoretical approach was used to derive the linear relationship between the applied load and the circumferential strain of the washer, which was directly measured by the FBG sensor. Taking advantage of an FBG sensor including its high sensitivity, the proposed smart washer can accurately measure the pre-load on a bolted joint. To validate the functionality of the FBG-enabled smart sensor for in situ bolt pre-load monitoring, a simple but effective testing apparatus was designed and fabricated. Experimental results demonstrate the linear relationship between the pre-load and the wavelength of the FBG sensor encircling the washer. Both analytical and experimental results reveal that the proposed novel approach is sensitive to the bolt pre-load and can monitor in real time the bolt looseness in the torque loading range. Future work will include incorporation of a temperature compensation scheme with the smart washer and analytical study of strain transfer from the washer to the FBG sensor.

Author Contributions: L.H., H.L. and G.S. conceived the original ideas. H.L., L.H. and G.S. designed the experiments. D.C. conducted the experiments. D.C. analyzed the data under advice from L.H. and G.S. G.S. planned the outline of the paper. D.C. wrote the paper under guidance from L.H. and G.S. H.L. made critical revisions to the paper.

Acknowledgments: This work was partially supported by the Major State Basic Research Development Program of China (973 Program, grant number 2015CB057704) and the National Natural Science Foundation of China (Grant number 51478080 and 51278084). The authors would like to thank them for their financial support.

Conflicts of Interest: The authors declare no conflicts of interest.

\section{References}

1. Pines, D.; Aktan, A.E. Status of structural health monitoring of long-span bridges in the United States. Prog. Struct. Eng. Mater. 2002, 4, 372-380. [CrossRef]

2. Yi, T.H.; Li, H.N.; Gu, M. Recent research and applications of GPS-based monitoring technology for high-rise structures. Struct. Contr. Health Monit. 2013, 20, 649-670. [CrossRef]

3. Brownjohn, J.; Moyo, P.; Omenzetter, P.; Chakraborty, S. Lessons from monitoring the performance of highway bridges. Struct. Contr. Health Monit. 2005, 12, 227-244. [CrossRef]

4. Mufti, A.A. Structural health monitoring of innovative Canadian civil engineering structures. Struct. Health Monit. 2002, 1, 89-103. [CrossRef]

5. Wong, K.Y. Instrumentation and health monitoring of cable-supported bridges. Struct. Contr. Health Monit. 2004, 11, 91-124. [CrossRef]

6. Du, G.; Kong, Q.; Zhou, H.; Gu, H. Multiple Cracks Detection in Pipeline Using Damage Index Matrix Based on Piezoceramic Transducer-Enabled Stress Wave Propagation. Sensors 2017, 17, 1812. [CrossRef] [PubMed] 
7. Kong, Q.; Robert, R.; Silva, P.; Mo, Y.L. Cyclic Crack Monitoring of a Reinforced Concrete Column under Simulated Pseudo-Dynamic Loading Using Piezoceramic-Based Smart Aggregates. Appl. Sci. 2016, 6, 341. [CrossRef]

8. Shao, J.; Wang, T.; Yin, H.; Yang, D.; Li, Y. Bolt Looseness Detection Based on Piezoelectric Impedance Frequency Shift. Appl. Sci. 2016, 6, 298. [CrossRef]

9. Yin, H.; Wang, T.; Yang, D.; Liu, S.; Shao, J.; Li, Y. A Smart Washer for Bolt Looseness Monitoring Based on Piezoelectric Active Sensing Method. Appl. Sci. 2016, 6, 320. [CrossRef]

10. Xu, J.; Wang, C.; Li, H.; Zhang, C.; Hao, J.; Fan, S. Health Monitoring of Bolted Spherical Joint Connection Based on Active Sensing Technique Using Piezoceramic Transducers. Sensors 2018, 18, 1727. [CrossRef] [PubMed]

11. Wang, T.; Song, G.; Liu, S.; Li, Y.; Xiao, H. Review of bolted connection monitoring. Int. J. Distrib. Sens. Netw. 2013, 9, 871213. [CrossRef]

12. Masataka, S.; Hasuo, Y.; Kanaya, A.; Ogura, Y.; Takishita, T.; Suzuki, Y. Development of ultrasonic axial bolting force inspection system for turbine bolts in thermal power plants. JSME Int. J. Solid Mech. Strength Mater. 1992, 35, 216-219.

13. Yao, P.; Zheng, B.; Dawood, M.; Huo, L.; Song, G. Real time monitoring of spot-welded joints under service load using lead zirconate titanate (PZT) transducers. Smart Mater. Struct. 2017, 26, 035059. [CrossRef]

14. Huo, L.; Chen, D.; Liang, Y.; Li, H.; Feng, X.; Song, G. Impedance based bolt pre-load monitoring using piezoceramic smart washer. Smart Mater. Struct. 2017, 26, 057004. [CrossRef]

15. Yasui, H.; Kawashima, K. Acoustoelastic measurement of bolt axial load with velocity ratio method. In Proceedings of the 15th World Conference on Non-Destructive Testing, Rome, Italy, 15-21 October 2000; pp. 16-21.

16. Wang, T.; Song, G.; Wang, Z.; Li, Y. Proof-of-concept study of monitoring bolt connection status using a piezoelectric based active sensing method. Smart Mater. Struct. 2013, 22, 087001. [CrossRef]

17. Huo, L.; Chen, D.; Kong, Q.; Li, H.; Song, G. Smart washer-A piezoceramic-based transducer to monitor looseness of bolted connection. Smart Mater. Struct. 2017, 26, 025033. [CrossRef]

18. Huo, L.; Wang, F.; Li, H.; Song, G. A fractal contact theory based model for bolted connection looseness monitoring using piezoceramic transducers. Smart Mater. Struct. 2017, in press. [CrossRef]

19. Park, G.; Sohn, H.; Farrar, C.R.; Inman, D.J. Overview of piezoelectric impedance-based health monitoring and path forward. Shock Vib. Dig. 2003, 35, 451-463. [CrossRef]

20. Yaowen, Y.; Bahador Sabet, D. Sub-Frequency Interval Approach in Electromechanical Impedance Technique for Concrete Structure Health Monitoring. Sensors 2010, 10, 11644-11661.

21. Enrique, S.; Sun, R.; Ricardo, P. Damage Detection Based on Power Dissipation Measured with PZT Sensors through the Combination of Electro-Mechanical Impedances and Guided Waves. Sensors 2016, 16, 639.

22. Fan, S.; Zhao, S.; Qi, B.; Kong, Q. Damage Evaluation of Concrete Column under Impact Load Using a Piezoelectric-Based EMI Technique. Sensors 2018, 18, 1591. [CrossRef] [PubMed]

23. Liang, C.; Sun, F.; Rogers, C. Coupled electro-mechanical analysis of adaptive material systems-determination of the actuator power consumption and system energy transfer. J. Intell. Mater. Syst. Struct. 1997, 8, 335-343. [CrossRef]

24. Park, G.; Cudney, H.H.; Inman, D.J. Feasibility of using impedance-based damage assessment for pipeline structures. Earthq. Eng. Struct. Dyn. 2001, 30, 1463-1474. [CrossRef]

25. Park, G.; Cudney, H.H.; Inman, D.J. Impedance-based health monitoring of civil structural components. J. Infrastruct. Syst. 2000, 6, 153-160. [CrossRef]

26. Lynch, J.P. A Summary Review of Wireless Sensors and Sensor Networks for Structural Health Monitoring. Shock Vib. Dig. 2006, 38, 91-128. [CrossRef]

27. Perera, R.; Pérez, A.; García-Diéguez, M.; Zapico-Valle, J.L. Active Wireless System for Structural Health Monitoring Applications. Sensors 2017, 17, 2880. [CrossRef] [PubMed]

28. Na, W.; Baek, J. Impedance-Based Non-Destructive Testing Method Combined with Unmanned Aerial Vehicle for Structural Health Monitoring of Civil Infrastructures. Appl. Sci. 2016, 7, 15. [CrossRef]

29. Tennyson, R.; Coroy, T.; Duck, G.; Manuelpillai, G.; Mulvihill, P.; Cooper, D.J.; Smith, P.E.; Mufti, A.; Jalali, S. Fibre optic sensors in civil engineering structures. Can. J. Civ. Eng. 2000, 27, 880-889. [CrossRef]

30. Li, H.-N.; Li, D.-S.; Song, G.-B. Recent applications of fiber optic sensors to health monitoring in civil engineering. Eng. Struct. 2004, 26, 1647-1657. [CrossRef] 
31. Tennyson, R.; Mufti, A.; Rizkalla, S.; Tadros, G.; Benmokrane, B. Structural health monitoring of innovative bridges in Canada with fiber optic sensors. Smart Mater. Struct. 2001, 10, 560-573. [CrossRef]

32. Ecke, W.; Latka, I.; Willsch, R.; Reutlinger, A.; Graue, R. Fibre optic sensor network for spacecraft health monitoring. Meas. Sci. Technol. 2001, 12, 974.

33. Zhou, Z.; He, J.; Huang, M.; He, J.; Chen, G. Casing pipe damage detection with optical fiber sensors: A case study in oil well constructions. Adv. Civ. Eng. 2010, 2010, 638967.

34. Chong, S.Y.; Lee, J.-R.; Yun, C.-Y.; Sohn, H. Design of copper/carbon-coated fiber Bragg grating acoustic sensor net for integrated health monitoring of nuclear power plant. Nucl. Eng. Des. 2011, 241, 1889-1898. [CrossRef]

35. Li, W.; Ho, S.C.M.; Luo, M.; Huynh, Q.; Song, G. Fiber optic macro-bend based sensor for detection of metal loss. Smart Mater. Struct. 2017, 26, 045002. [CrossRef]

36. Khomenko, A.; Koricho, E.G.; Haq, M.; Cloud, G.L. Bolt tension monitoring with reusable fiber Bragg-grating sensors. J. Strain Anal. Eng. Des. 2015, 51, 101-108. [CrossRef]

37. Khomenko, A.; Koricho, E.G.; Haq, M.; Cloud, G.L. Short-Term Preload Relaxation in Composite Bolted Joints Monitored with Reusable Optical Sensors. In Joining Technologies for Composites and Dissimilar Materials, Proceedings of the 2016 Annual Conference on Experimental and Applied Mechanics, Orlando, FL, USA, 6-9 June 2016; Springer: Berlin, Germany, 2016; pp. 115-123.

38. Yeager, M.; Whitaker, A.; Todd, M. A method for monitoring bolt torque in a composite connection using an embedded fiber Bragg grating sensor. J. Intell. Mater. Syst. Struct. 2017. [CrossRef]

39. Büyüköztürk, O.; Taşdemir, M.A. Nondestructive Testing of Materials and Structures; Springer Science \& Business Media: Berlin, Germany, 2012; Volume 6.

40. Majumder, M.; Gangopadhyay, T.K.; Chakraborty, A.K.; Dasgupta, K.; Bhattacharya, D.K. Fibre Bragg gratings in structural health monitoring-Present status and applications. Sens. Actuators A Phys. 2008, 147, 150-164. [CrossRef]

41. Ren, L.; Feng, T.; Ho, M.; Jiang, T.; Song, G. A smart "shear sensing" bolt based on FBG sensors. Measurement 2018, 122, 240-246. [CrossRef]

42. Bray, A.; Levi, R. Factors affecting the tightening characteristics of bolts. Exp. Mech. 1966, 6, 409-419. [CrossRef]

43. Eccles, W. Design Guidelines for Torque Controlled Tightening of Bolted Joints; 0148-7191; SAE Technical Paper; SAE: Warrendale, PA, USA; Troy, MI, USA, 1993.

44. Fukuoka, T.; Takaki, T. Mechanical behaviors of bolted joint during tightening using torque control. JSME Int. J. Ser. A Solid Mech. Mater. Eng. 1998, 41, 185-191. [CrossRef]

45. Sakai, T. The friction coefficient of fasteners. Bull. JSME 1978, 21, 333-340. [CrossRef]

46. Motosh, N. Development of design charts for bolts preloaded up to the plastic range. J. Eng. Ind. 1976, 98, 849-851. [CrossRef]

47. Jiang, Y.; Chang, J.; Lee, C.-H. An experimental study of the torque-tension relationship for bolted joints. Int. J. Mater. Prod. Technol. 2001, 16, 417-429. [CrossRef]

(C) 2018 by the authors. Licensee MDPI, Basel, Switzerland. This article is an open access article distributed under the terms and conditions of the Creative Commons Attribution (CC BY) license (http:/ / creativecommons.org/licenses/by/4.0/). 